\title{
Accommodation of Plastic Deformation by Ultrasound-Induced Grain Rotation
}

\author{
R.K. DUTTA, R.H. PETROV, M.J.M. HERMANS, and I.M. RICHARDSON \\ Electron backscatter diffraction was used to investigate the softening effect in low-carbon steel \\ [Fe-0.051C-0.002Si-0.224Mn-0.045Al (wt pct)] during tensile deformation with in situ ultrasonic \\ treatment. A bimodal grain size distribution is observed with relatively small equiaxed grains \\ with an average diameter of $10 \mu \mathrm{m}$ at the grain boundaries of large elongated grains. The \\ formation of these relatively small equiaxed grains is interpreted in terms of dynamic recrys- \\ tallization by lattice and sub-grain rotation.
}

DOI: $10.1007 / \mathrm{s} 11661-015-2910-8$

(C) The Minerals, Metals \& Materials Society and ASM International 2015

\section{INTRODUCTION}

HiGH frequency peening, and in particular, ultrasonic methods, such as ultrasonic peening and ultrasonic impact treatment are used more and more to alter the fatigue lifetime of welded components. Although reported results on fatigue life are very promising, ${ }^{[1,2]}$ the detailed changes induced in the treated material and the mechanisms by which such changes occur are poorly understood. Ultrasonic impact treatment consists of an ultrasonic and a mechanical impact component. However, it is known that ultrasound absorption can lead to movement and creation of dislocations. The softening effect (reduction of the quasi-static stress) of superimposed ultrasonic vibrations on metals and alloys undergoing deformation is a well-known effect. ${ }^{[3-10]}$ There are different hypotheses for the mechanism behind the changes in the material properties during ultrasonic excitation. Langenecker ${ }^{[5]}$ proposed that ultrasound induces a change in the dislocation distribution as well as activation of new dislocation sources, occurring as a result of preferential energy absorption at defects in the crystalline lattice. An increase in dislocation mobility allows the metal to deform at a lower load. Other hypotheses include (i) the superposition of stresses ${ }^{[1-15]}$ (ii) thermal softening of materials, ${ }^{[16]}$ and (iii) the effect of a change in surface friction between the ultrasonic tool and the deformed material. ${ }^{[11]}$ Existing theoretical models for stress superposition ${ }^{[12-14]}$ assume that the intrinsic resistance to deformation of the metal is not

R.K. DUTTA, PhD Researcher, is with the Materials innovation institute M2i, Mekelweg 2, 2628 CD Delft, The Netherlands, and also with the Department of Materials Science and Engineering, Delft University of Technology, Mekelweg 2, 2628 CD Delft, The Netherlands.Contact e-mail: Rangan.dutta@gmail.com,r.k.dutta@ tudelft.nl, r.dutta@m2i.nl R.H. PETROV, Professor, is with the Department of Materials Science and Engineering, Delft University of Technology, and also with the Department of Materials Science and Engineering, Ghent University, Technologiepark 903, 9052 Ghent, Belgium. M.J.M. HERMANS, Assistant Professor, and I.M. RICHARDSON, Professor, are with the Department of Materials Science and Engineering, Delft University of Technology.

Manuscript submitted July 29, 2014.

Article published online June 13, 2015 affected by the ultrasound, but with ultrasonic vibration the total stress applied to the sample is higher than the stress applied by the loading machine, because the ultrasonic vibrations also produce oscillatory stresses. The study by Daud et al. ${ }^{[17]}$ showed that the reduction in mean stress is greater than the amplitude of oscillatory stress provided by the ultrasonic excitation, indicating that superposition of stress is inadequate to explain the stress reduction. As for thermal softening, previous studies ${ }^{[5,16-21]}$ reported no or an insignificant specimen temperature rise during experiments, indicating that ultrasonic softening cannot merely be a thermal effect.

Despite the considerable modeling and experimental effort to date, there is still no clear and comprehensive understanding of the mechanisms responsible for the acoustoplastic effect. In particular, it is still uncertain whether the effect of ultrasonic vibration on metal plasticity is extrinsic (factors like superimposed stress waves to supplement the quasi-static load and temperature) and/or intrinsic (factors like dislocation mobility). It is therefore of special interest to study the influence of ultrasonic treatment on materials in the plastically stressed condition. We have previously shown ${ }^{[22]}$ a substantial reduction of sub-grains and low-angle grain boundaries with in situ ultrasonic treatment during tensile deformation of low-carbon steel and suggested that plastic deformation is accommodated by ultrasound-induced grain boundary rotation. In the present work, we explore the possibility of the reduction in lowangle grain boundaries by grain rotation further. To this end, investigations on the role of in situ ultrasonic treatment on the microstructure and sub-grain structure of low-carbon steel during tensile deformation were performed using optical microscopy and electron backscatter diffraction (EBSD).

\section{EXPERIMENTAL}

In this study, a tensile deformation was applied using an electro-mechanical Instron tensile testing machine. DC04 steel specimens were examined with and without ultrasonic vibration applied in a direction normal to the 
Table I. Chemical Composition of DC04 Steel from Ladle in Weight Percent

\begin{tabular}{lcccccccccc}
\hline $\mathrm{C}$ & $\mathrm{Si}$ & $\mathrm{Mn}$ & $\mathrm{Al}$ & $\mathrm{P}$ & $\mathrm{S}$ & $\mathrm{V}$ & $\mathrm{Ti}$ & $\mathrm{N}$ & $\mathrm{Fe}$ \\
\hline 0.051 & 0.002 & 0.224 & 0.045 & 0.008 & 0.011 & 0.001 & 0.001 & 0.0037 & bal. \\
\hline
\end{tabular}

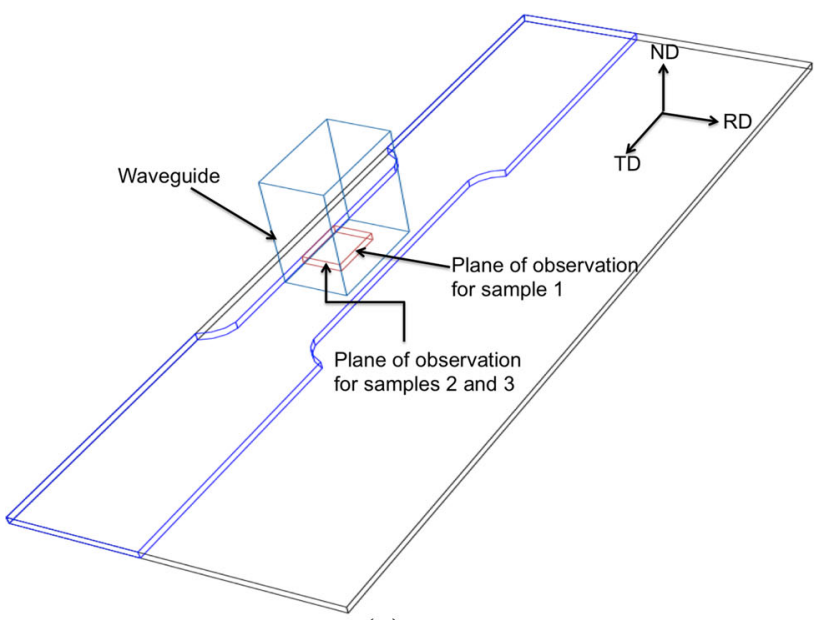

(a)

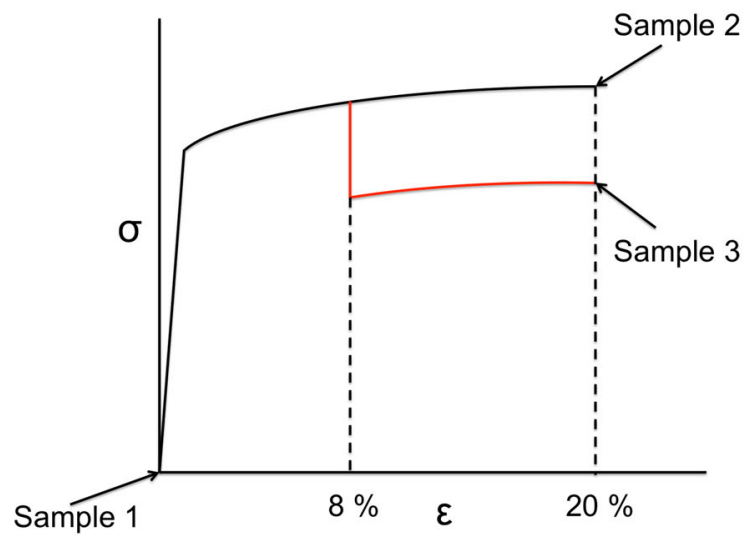

(b)

Fig. 1-Schematic view of (a) sample orientation. RD, TD, and ND correspond to the rolling, transverse, and normal direction of the rolled sheet and $(b)$ test conditions. The red curve shows the tensile curve superimposed with ultrasonic vibrations.

tensile axis. Factors including the duration of the ultrasonic excitation and heating up of the sample during tensile deformation were investigated. The crosssectional deformation microstructure was analyzed using optical microscopy, scanning electron microscopy (SEM), and EBSD, in order to elucidate the effects of the ultrasound vibration.

\section{A. Sample Preparation}

Commercial sheets of 2-mm-thick low-carbon DC04 steel with chemical composition presented in Table I were cut into tensile samples perpendicular to the rolling direction (RD) (see Figure 1(a)) according to the ASTM-E8/E8M-09 ${ }^{[23]}$ standard. The tensile samples were then heat treated by austenitizing at $1163 \mathrm{~K}$ $\left(890^{\circ} \mathrm{C}\right.$ ) for 1 hour in a salt bath furnace followed by air cooling to room temperature to minimize the stresses in the sample due to machining. The heat treated samples were electro-polished in a solution of $700 \mathrm{~mL}$ ethanol (absolute), $120 \mathrm{~mL}$ distilled water, $100 \mathrm{~mL}$ glycerol, and $80 \mathrm{~mL}$ perchloric acid ${ }^{[24]}$ to avoid the formation of dislocations at the surface due to grinding and polishing.

\section{B. Tensile Deformation with In Situ Ultrasonic Treatment}

The ultrasonic treatment of the heat treated and polished samples was carried out by excitation via a waveguide. The oscillation amplitude and frequency were $26 \mu \mathrm{m}$ and $27 \mathrm{kHz}$, respectively. The contact force between the waveguide and tensile sample was maintained at approximately $50 \mathrm{~N}$ via a spring loaded cell, ensuring good contact between the waveguide and the sample surface while avoiding sample bending. The ultrasonic treatment was applied in situ during tensile deformation between strain levels of 8 and 20 pct. The cross-head displacement velocity was $2.7 \mathrm{~mm} \mathrm{~min}^{-1}$. Using an extensometer with a gage length of $20 \mathrm{~mm}$, elongation was recorded for the applied load. Three cases are considered: (1) 0 pct strain, (2) 20 pct strain and (3) 20 pct strain with in situ ultrasonic treatment during tensile deformation between strain levels of 8 and 20 pct (samples 1, 2, and 3, respectively, see Figure 1(b)).

\section{Microstructure Characterization}

To prepare samples for optical microscopy, EBSD, and X-ray diffraction, the tensile specimens were sectioned along the normal direction (ND) either transverse (TD) or parallel to the RD for all the cases (see Figure 1(a)). The sectioned specimens for EBSD were first plane ground with $\mathrm{SiC}$ paper to a 2400 grit finish, followed by fine polishing with diamond paste to a $1 \mu \mathrm{m}$ finish. Finally, the surface was electro-polished using a solution of $700 \mathrm{~mL}$ ethanol, $120 \mathrm{~mL}$ distilled water, $100 \mathrm{~mL}$ butoxyethanol, and $80 \mathrm{~mL}$ perchloric acid. ${ }^{\text {[24] }}$

The EBSD scans were carried out on a NOVA 600 focused ion beam scanning electron microscope (SEM) equipped with a field emission gun operating at an accelerating voltage of $15 \mathrm{kV}$, a beam current of $0.59 \mathrm{nA}$, and a working distance of $7 \mathrm{~mm}$. The sample was tilted at $70 \mathrm{deg}$ to the horizontal axis for the EBSD scans and a step size of $0.25 \mu \mathrm{m}$ in a square scan grid measuring $175 \times 175 \mu \mathrm{m}^{2}$ was used for all the scans. By choosing an optimum image resolution for pattern processing and by optimizing the Hough transform parameters, an angular resolution of better than $0.5 \mathrm{deg}$ was obtained. The lateral resolution of the system is around $30 \mathrm{~nm}$ parallel to the tilt axis and around $90 \mathrm{~nm}$ perpendicular to the tilt axis, determined on iron at $15 \mathrm{kV} .^{[25]}$ The scans were made in the center of the 


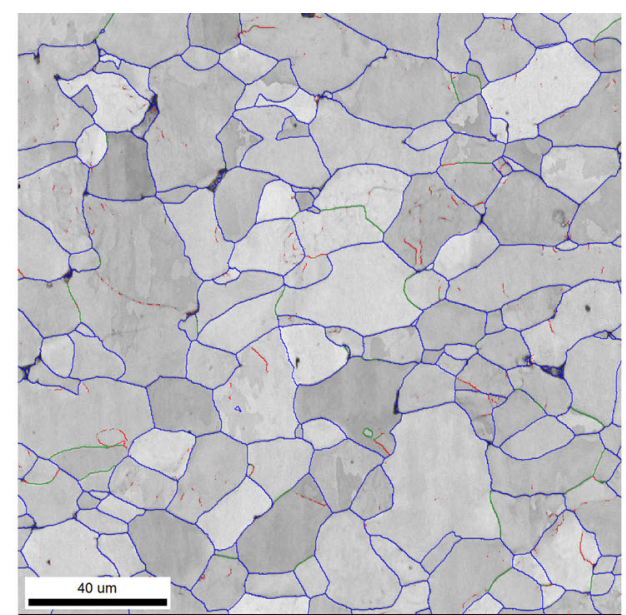

(a)

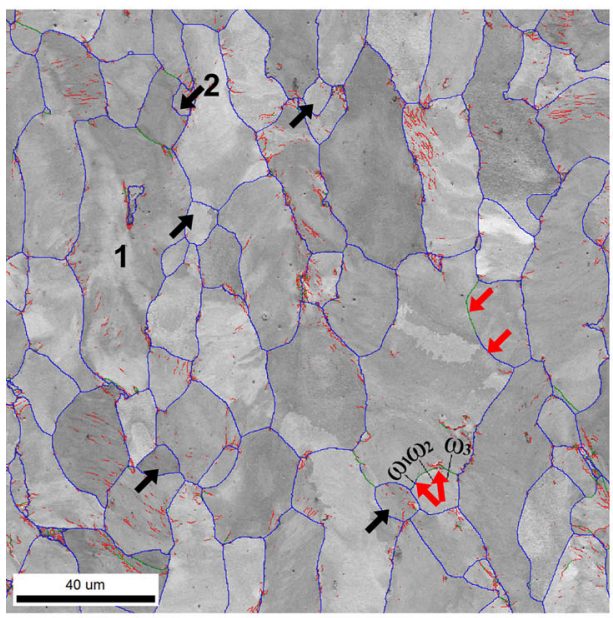

(c)

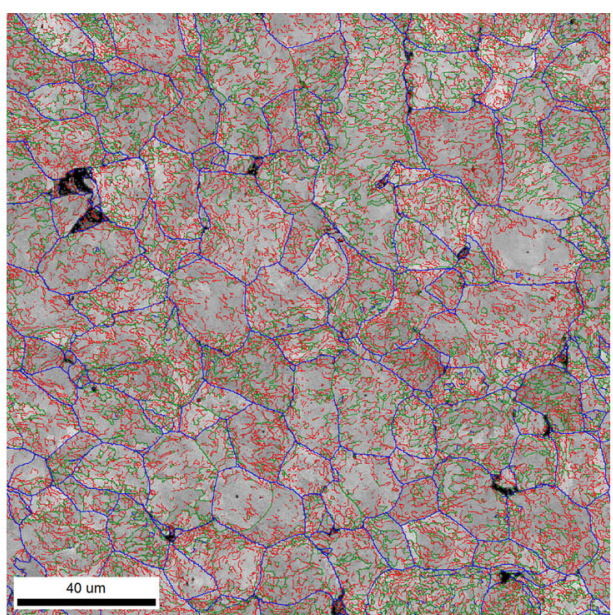

(b)

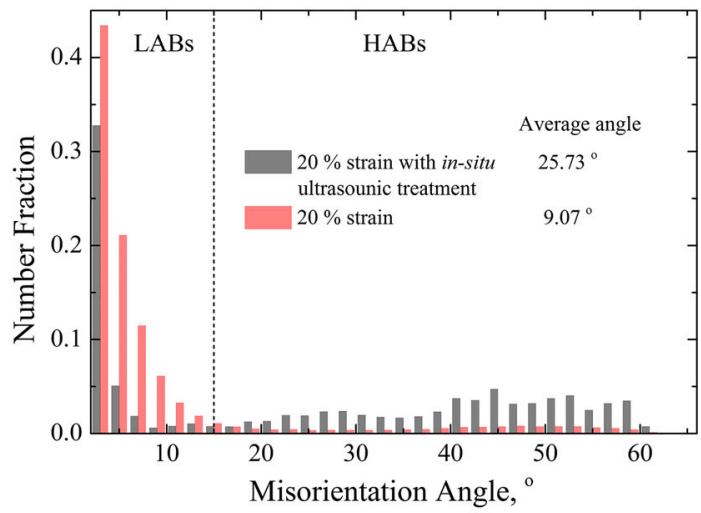

(d)

Fig. 2-EBSD characterization of the cross section of the low-carbon steel. Image quality map with low-angle boundaries and high-angle boundaries for $(a) 0$ pct deformation, (b) 20 pct deformation without in situ ultrasonic treatment, and (c) in situ ultrasonic treatment during tensile deformation between strain levels of 8 and 20 pct. $\omega_{1}=16.6 \mathrm{deg}, \omega_{2}=13.1 \mathrm{deg}$, and $\omega_{3}=13.1 \mathrm{deg}$ represent the boundary misorientation between the adjacent grains. (d) Grain boundary misorientation angle distribution for the deformed steel with and without in situ ultrasonic treatment.

sample at a depth of around $1 \mathrm{~mm}$. The EBSD data were post-processed by means of $\mathrm{TSL}^{\circledR}$ - Orientation Imaging Microscopy (OIM $\left.{ }^{\mathrm{TM}}\right)$ data analysis software. 98 pct of the points were indexed and the remaining 2 pct misindexed points were eliminated from the EBSD maps during post-processing. The differences of grain orientation greater than $15 \mathrm{deg}$ were defined as highangle grain boundaries (HABs) and denoted by the blue lines, while those lower than 15 deg were defined as lowangle grain boundaries (LABs) in Figures 2(b) and (c). The low-angle grain boundaries were again discretized between 2 deg to $5 \mathrm{deg}$ and $5 \mathrm{deg}$ to $15 \mathrm{deg}$ denoted by red and green lines, respectively.

\section{RESULTS AND DISCUSSION}

\section{A. Microstructure Evolution}

Cross sections of the low-carbon steel without and with in situ ultrasonic treatment during tensile deformation are shown in Figure 2. It is evident that the in situ ultrasonic treatment significantly reduces the number of sub-grains. The histogram of grain size distribution of the low-carbon steel without and with in situ ultrasonic treatment is shown in Figure 3. The deformation is more homogeneous without in situ ultrasonic treatment as is evident from the grain size distributions (Figures 3(a) and (b)). With in situ ultrasonic treatment, the deformation is clearly inhomogeneous, as shown by the mixture of equiaxed grains [shown by black arrows in Figure 2(c)] and very elongated grains (bimodal grain size distributions in Figures 3(c) and (d)). These relatively small equiaxed grains measuring between 5 and $15 \mu \mathrm{m}$ in diameter are observed at the grain boundaries of large elongated grains. The EBSD observations imply that the formation of relatively small equiaxed grains is attributed to dynamic recrystallization in the process of deformation, rather than static recrystallization during a heating and cooling process, because a typical feature of grains formed by static recrystallization is that they are nearly 


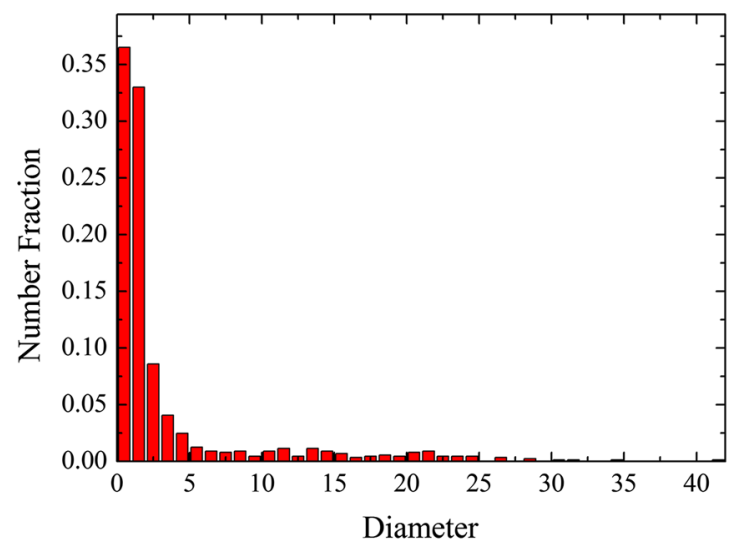

(a)

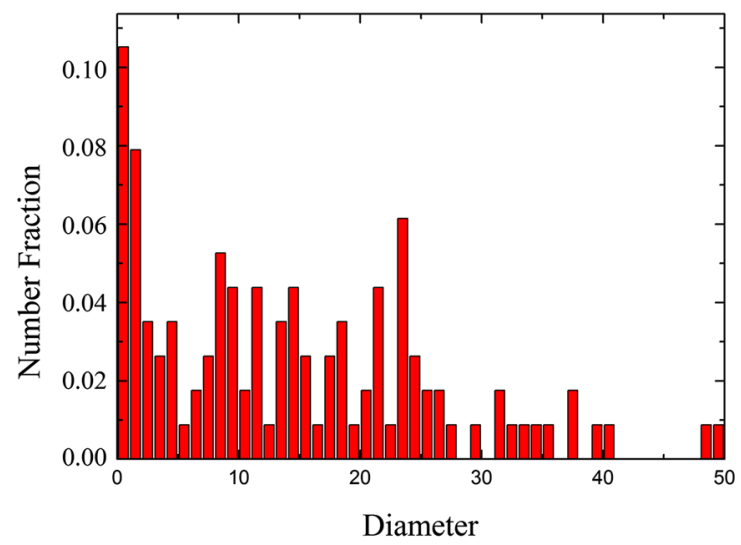

(c)

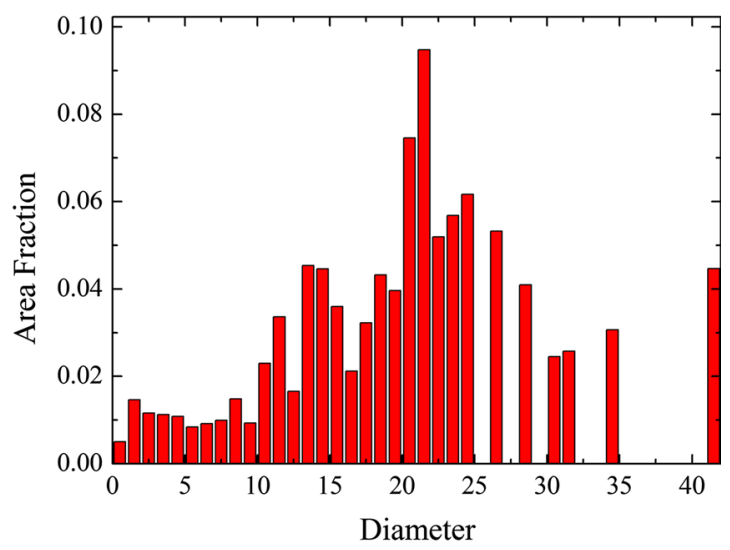

(b)

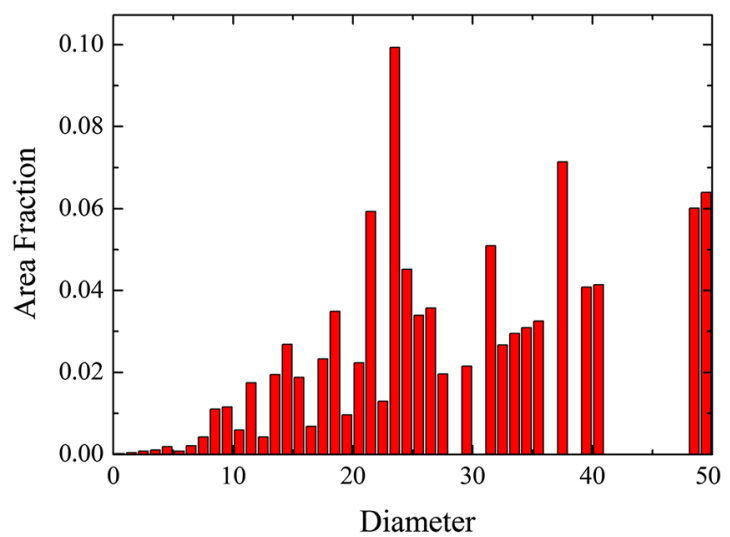

(d)

Fig. 3 - Grain size distribution of the steel without ultrasonic treatment: $(a)$ diameter as a function of number fraction and (b) diameter as a function of area fraction. Grain size distribution of the steel with in situ ultrasonic treatment: $(c)$ diameter as a function of number fraction and (d) diameter as a function of area fraction.

strain/defect free. ${ }^{[26]}$ The occurrence of dynamic recrystallization is supported in a more quantitative manner by the distributions of misorientations between neighboring crystallites (Figure 2(d)). Without in situ ultrasonic treatment, a large fraction of misorientations is below $15 \mathrm{deg}$, which is due to the continuous generation of sub-grain boundaries. The fraction of misorientation between $15 \mathrm{deg}$ and $63 \mathrm{deg}$, corresponding to high-angle boundaries, increases significantly in the in situ ultrasonic-treated sample, which may be attributed to the progressive transformation of sub-grain boundaries into grain boundaries (shown by red arrows in Figure 2(c)).

The grain orientation spread (GOS) parameter corresponds, for one grain, to the average deviation between the orientation of each point in the grain and the average orientation of the grain. ${ }^{[27]}$ Figure 4(a) shows the GOS map of the ultrasonically treated sample. Figure 4(b) shows the image quality (IQ) map of the low-carbon steel with in situ ultrasonic treatment, where the grains with average grain diameter $<15 \mu \mathrm{m}$ are highlighted in blue. The GOS distributions were plotted for the grains with average grain diameter $<15$ and $>15 \mu \mathrm{m}$. The grains with average grain diameter $<15 \mu \mathrm{m}$ show a lower average spread compared to the grains with average grain diameter $>15 \mu \mathrm{m}$ indicating that the larger grains have undergone greater plastic deformation. Local lattice rotations can be quantitatively analyzed using the Grain Reference Orientation Deviation (GROD) function. ${ }^{[27]}$ This tool reveals the angular deviation of each point relative to a given reference orientation, e.g., a point representing the stable grain interior far away from the grain boundary interface. In the present case, the grain average orientation is used as the reference. Figure 5(a) shows such GROD maps in which the color code given in the index reveals those areas that are highly misorientated with respect to the grain average orientation. Figure 5(b) shows the kernel average misorientation (KAM) map of the same area. KAM in combination with GOS can be used to estimate plastic deformation. ${ }^{[27]}$ In fact, Kamaya ${ }^{[28]}$ has shown that the GOS is an even better tool than KAM, as it is less affected by the measurement conditions. The KAM criterion can also be used to determine geometrically necessary dislocation concentrations in grains of different orientations. Kamaya ${ }^{[29]}$ has shown that comparing KAM values for near grain boundary regions with the average KAM value of the neighboring grains may give information about concentration or localization of geometrically necessary dislocations. If the two values are similar, this means that dislocations are uniformly distributed in the grain, 


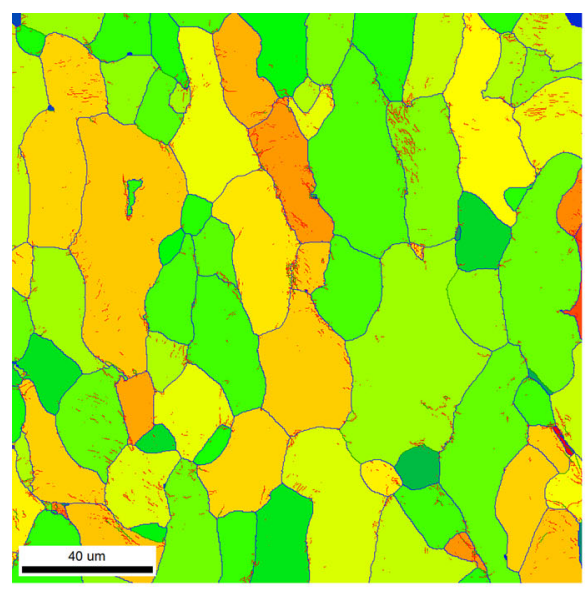

(a)

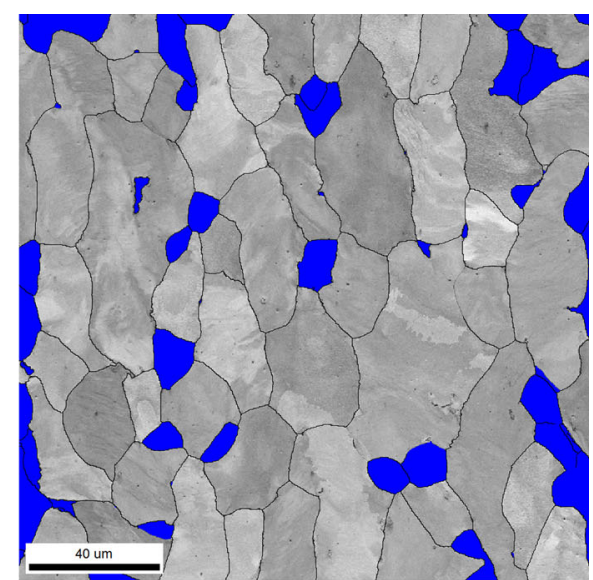

(b)

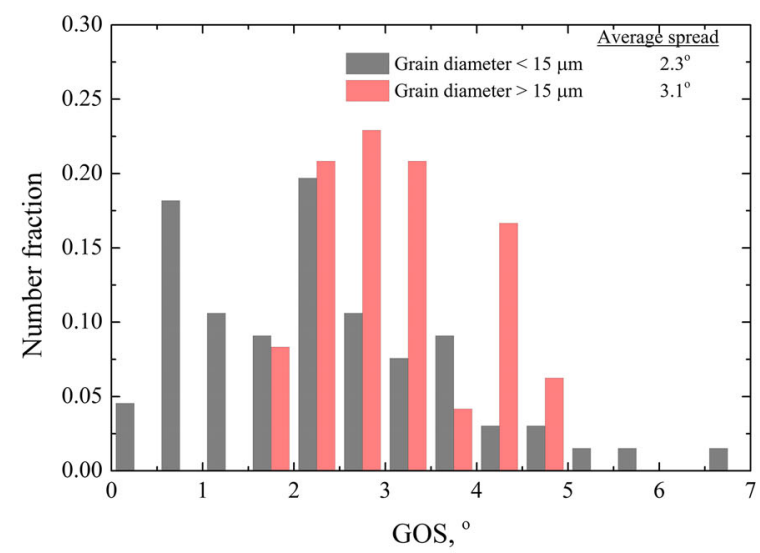

(c)

Fig. 4 - (a) Grain orientation spread map of the ultrasonically treated sample. (b) Image quality map of the low-carbon steel with in situ ultrasonic treatment during tensile deformation between strain levels of 8 and 20 pct. The grains with average grain diameter $<15 \mu \mathrm{m}$ are highlighted in blue. (c) Experimentally determined grain orientation spread distribution for the grains with average grain diameter $<15$ and $>15 \mu \mathrm{m}$.

whereas a KAM value for near grain boundary regions higher than the average KAM of the grain means that dislocations are mainly located in grain boundary regions. This effect can be easily visualized with the help of the GROD maps (Figure 5(a)) as it is normalized to the grain average orientation. It is seen that in the smaller grains (with grain diameter less that $15 \mu \mathrm{m}$ ), the grain reference orientation deviation is higher closer to the grain boundaries than in the grain interior [see for example Figure 5(c) for the case of grain 2 from Figure 2(c)].

There are two possible mechanisms for dynamic recrystallization: rotational and migrational types. ${ }^{[30]}$ One way to determine which of these is operating is to consider the change in misorientation moving from the original grains to the recrystallized region..$^{[31,32]}$ Figure 6(a) is the combined IQ and color-coded inverse pole figure (IPF) map of grains 1 and 2 from Figure 2(c). The point-to-point and the point-to-origin misorientations are plotted as a function of distance along path $\mathrm{ABCD}$ from the elongated grain (ABC) to the center (D) of the equiaxed grain, as shown in Figure 6(b). It is seen that there are three apparently different regions divided by points A, B, C, and D in Figures 6(a) through (c), showing the distinct microstructures and the corresponding misorientations. Moving from A to B, the IQ decreases and there is a gradual accumulation of $\sim 6.5 \mathrm{deg}$ of misorientation over $\sim 12.5 \mu \mathrm{m}$ indicating long range lattice rotations within this grain (Figure $6(\mathrm{~b})$ ). The misorientation gradient in this region is relatively low indicating low lattice strain and defect density. Moving from $\mathrm{B}$ to $\mathrm{C}$, there is a sharp peak in the point-to-point misorientation at $\sim 19 \mu$ m indicating the presence of a low angle or sub-grain boundary. The misorientation gradient across the sub-grain boundary reaches an average value of $30 \mathrm{deg} \mu \mathrm{m}^{-1}$. Crossing into the equiaxed grain, (moving from $\mathrm{C}$ to $\mathrm{D}$ ), the misorientation reaches the highest value $(\sim 58 \mathrm{deg}$ at $\sim 30 \mu \mathrm{m})$ indicating the presence of a high-angle grain boundary.

To further reveal the deformation induced lattice rotation in one grain (grain 1 from Figure 2(c)), the tolerance angle map (Figure 6(c)) is illustrated using the color gradient from blue to red. Moving from point A to $\mathrm{D}$, it can be seen that the lattice is gradually rotated. The tolerance angle gradually increases across the sub-grain boundary (between point $\mathrm{B}$ and $\mathrm{C}$ ) reaching maximum close to the high-angle boundary (between point $\mathrm{C}$ and D). The lattice rotations along the line $\mathrm{ABCD}$ are also 


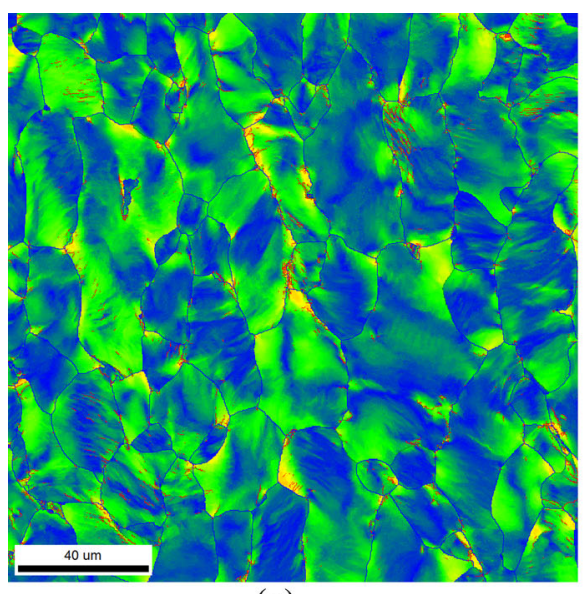

(a)

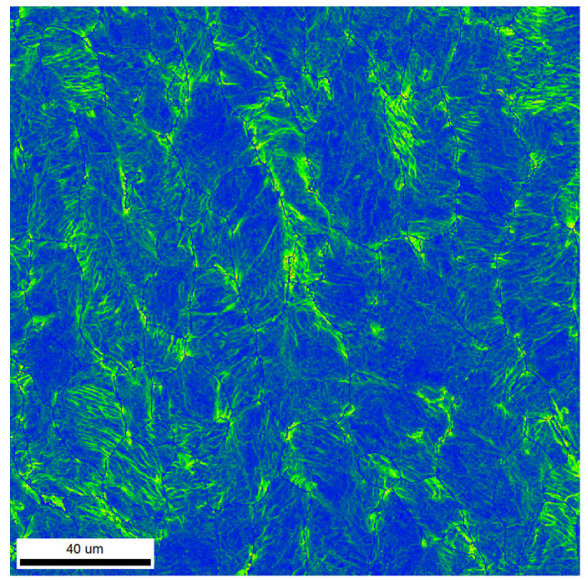

(b)
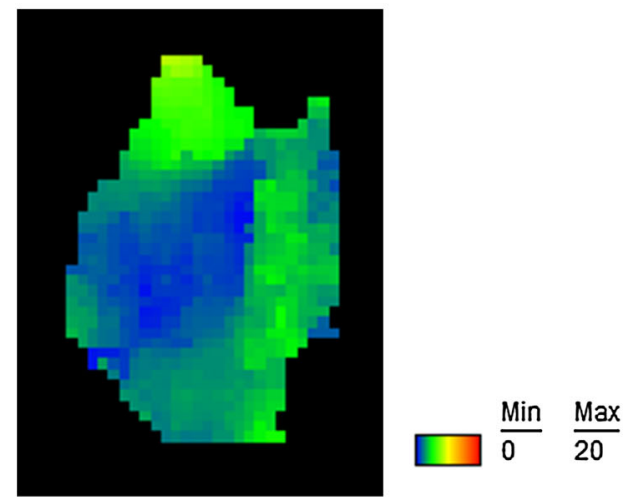

(c)

Fig. 5-Low-carbon steel with in situ ultrasonic treatment during tensile deformation between strain levels of 8 and 20 pct. (a) Grain reference orientation deviation map with grain average orientation as the reference. (b) Kernel average misorientation map. (c) GROD map of grain 2 from Fig. 2(c).

illustrated using the IPFs (Figures 6(d) and (e)) and Table II. These results show that the lattice in the elongated grain is progressively rotated until high-angle boundaries appear at the equiaxed grain. Similar observations were made in other pairs of elongated and equiaxed grains (see for example Figures 4(b) and (c)).
Dynamic recrystallization can be classified into either continuous or discontinuous recrystallization. ${ }^{[33]}$ In general, during continuous recrystallization, dislocations will remain in the recrystallized grains, whereas discontinuous recrystallization removes dislocations through the sweeping action of high-angle boundaries. Continuous recrystallization is also considered as a recovery-dominated process, where there will be a progressive increase in boundary misorientation and conversion of low-angle boundaries into high-angle boundaries.

In the present work, dislocations are observed in the smaller equiaxed recrystallized grains, primarily along the grain boundaries. Well-defined sub-grain boundaries were rarely observed in the recrystallized grains interior, inferring that sub-grain boundary misorientation increased during deformation with in situ ultrasonic treatment and low-angle grain boundaries transformed into high-angle boundaries. Evidence of this transformation can be found in Figure 2(c) (shown by red arrows). The boundary misorientation $\omega$ between the adjacent grains increases from $\omega_{3}=13.1 \mathrm{deg}$ to $\omega_{1}=$ $16.6 \mathrm{deg}$ indicating progressive transformation of subgrain boundaries into grain boundaries.

\section{B. Conceptual Modeling of Microstructure Evolution}

Based on the present observations, it is reasonable to propose a model describing a mechanism for dynamic recrystallization occurring with in situ ultrasonic treatment. The dislocation distribution is homogeneous without ultrasonic treatment (Figure 2(b)). As a consequence of in situ ultrasonic treatment, the original grains are elongated into substructures. Dislocations accumulate at substructure boundaries leading to the break up of the elongated substructures. As the sub-boundaries reorient, there is an increase in orientation difference at the boundaries followed by rotation of sub-boundaries and the formation of recrystallized grains with highangle boundaries. This conceptual model is, in fact, in good agreement with those proposed by $\mathrm{Xu}$ et al. ${ }^{[34]}$ and Liet al. ${ }^{[35]}$ This sequence of events, which is well known for severe plastic deformation, has been given different names in the literature: (1) Rotational dynamic recrystallization (e.g., Derby, ${ }^{[30]}$ ), which needs concurrent plastic deformation, is well documented for geological materials. This was the interpretation given in adiabatic shear bands by Meyers et al., ${ }^{[36,37]}$ for titanium, Andrade et al. ${ }^{[38]}$ for copper, and Nesterenko et al. ${ }^{[39]}$ for tantalum. (2) Formation of geometrically necessary boundaries. ${ }^{[40-46]}$ (3) Continuous recrystallization. ${ }^{[47,48]}$ Once this equiaxed fine grain structure is achieved, it can undergo additional plastic deformation under the imposed conditions.

\section{Grain Elongation Due to Ultrasound}

When an ultrasonic wave transmits through a solid it can disturb the structure, which gives rise to internal forces that tend to return the body to equilibrium. The stresses associated with the propagation of ultrasonic waves are the basic cause of the numerous mechanical 
effects attributable to changing the material microstructure. ${ }^{[49]}$ The stress produced by an ultrasonic wave $\sigma_{U S}$ traveling through a solid may be calculated as follows: $:^{[50,51]}$

$$
\sigma_{U S}=\xi \rho \omega c,
$$

where $\xi$ is the particle displacement, $\rho$ is the density, $\omega$ is the angular frequency, and $c$ is the wave velocity in the specimen. In this study $\xi=28 \mu \mathrm{m}, \rho=7870 \mathrm{~kg} \mathrm{~m}^{-3}$, $\omega=2 \pi f=1,69,650 \mathrm{~Hz}$, and $c=5130 \mathrm{~m} \mathrm{~s}^{-1}$. Therefore, the stress caused by the ultrasonic vibration $\sigma_{U S}$ is $192 \mathrm{MPa}$. This stress acts sinusoidally on top of the axial deformation during plastic deformation of the sample. ${ }^{[49]}$ A vibratory stress relief process is a type of cyclic creep. ${ }^{[52-55]}$ Softening and creep are parallel cyclic behaviors during cyclic loading of prestrained metals. The softening behavior is associated with mutual annihilation of dislocations paired with opposite signs

Table II. Euler Angles of the Cubes Marked 1 to 10 in Fig. 6(a)

\begin{tabular}{|c|c|c|c|}
\hline Cube Number & $\begin{array}{c}\text { Euler Angles } \\
{[\varphi 1, \Phi, \varphi 2]}\end{array}$ & $(h k l)$ & {$\left[\begin{array}{lll}u & v & w\end{array}\right]$} \\
\hline $1(\mathrm{~A})$ & {$[15.0,44.9,22.9]$} & $\left(\begin{array}{lll}9 & 23 & 25\end{array}\right)$ & {$\left[\begin{array}{lll}17 & -11 & 4\end{array}\right]$} \\
\hline 2 & {$[13.7,43.9,26.2]$} & $\left(\begin{array}{lll}5 & 11 & 12\end{array}\right)$ & {$\left[\begin{array}{lll}19 & -13 & 4\end{array}\right]$} \\
\hline 3 & {$[230.3,47.1,64.6]$} & $\left(\begin{array}{lll}17 & 8 & 18\end{array}\right)$ & {$\left[\begin{array}{lll}2 & 7 & -5\end{array}\right]$} \\
\hline $4(\mathrm{~B})$ & {$[232.2,45.8,64.2]$} & $\left(\begin{array}{lll}22 & 11 & 24\end{array}\right)$ & {$\left[\begin{array}{lll}4 & 16 & -11\end{array}\right]$} \\
\hline 5 & {$[234.8,45.1,66.6]$} & $\left(\begin{array}{lll}12 & 5 & 13\end{array}\right)$ & {$\left[\begin{array}{lll}7 & 17 & -13\end{array}\right]$} \\
\hline 6 & {$[242.9,47.7,53.6]$} & $(869)$ & {$\left[\begin{array}{lll}3 & 11 & -10\end{array}\right]$} \\
\hline $7(\mathrm{C})$ & {$[241.2,49.9,53.7]$} & $\left(\begin{array}{lll}3 & 2 & 3\end{array}\right)$ & {$\left[\begin{array}{lll}3 & 12 & -11\end{array}\right]$} \\
\hline 8 & {$[240.3,50.2,56.1]$} & $\left(\begin{array}{lll}3 & 2 & 3\end{array}\right)$ & {$\left[\begin{array}{lll}3 & 12 & -11\end{array}\right]$} \\
\hline 9 & {$[85.6,25.7,33.2]$} & $\left(\begin{array}{lll}7 & 11 & 27\end{array}\right)$ & {$\left[\begin{array}{lll}-11 & -20 & 11\end{array}\right]$} \\
\hline 10 (D) & {$[82.3,25.1,36.8]$} & $\left(\begin{array}{lll}5 & 7 & 19\end{array}\right)$ & {$\left[\begin{array}{lll}-1 & -2 & 1\end{array}\right]$} \\
\hline
\end{tabular}

(glide) and the rearrangements (climb) of the residual dislocations (identical signs) that form low-energy structures. The cyclic creep is interpreted as being caused by the Bauschinger effect of the prestrained metal. Excess dislocations with the same sign result in a back stress and favors dislocation motion in the direction opposite to that of the prestrain. Thus, cyclic creep occurs in compression. ${ }^{[56,57]}$ The existence of this complex stress state within the cross section of the sample might cause the elongation of the grains along the RD orientation (see Figure 1(a) for reference). Such grain elongation during ultrasonic-assisted deformation processes has also been reported previously. ${ }^{[49,58]}$

\section{Recrystallized Grain Diameter}

Experiments on dynamic recrystallization ${ }^{[47,59]}$ suggest that the recrystallized grain size $\left(D_{R}\right)$ may be estimated using a simple relationship: $\frac{\sigma}{G} \cdot\left(\frac{D_{R}}{b}\right)^{n}=K$, where $\sigma$ is applied stress, $n$ and $K$ are constants (being 0.8 and 15, respectively), $b$ is the Burgers vector $(0.248 \mathrm{~nm}$ for iron), and $G$ is the shear modulus (80 GPa for steel). The applied stress $\sigma$ during in situ ultrasonic treatment at 20 pct strain was about $255 \mathrm{MPa}$ and the calculated dynamic recrystallized grain size $\left(D_{R}\right)$ is about $10 \mu \mathrm{m}$, which is in good agreement with the observed grain size by EBSD. Empirical equations (Eq. [2]) to estimate the average steady-state grain sizes during recrystallization ${ }^{[60-62]}$ yielded $\bar{D}=7 \mu \mathrm{m}$.

$$
\bar{D}=38.26\left(\frac{Z}{A}\right)^{-0.08} \mu \mathrm{m}
$$

where $Z=\dot{\varepsilon} \exp \frac{Q_{\text {deformation }}}{R T}$ is the Zener-Hollomon parameter and $Q_{\text {deformation }}$ is the activation energy of deformation. $Q_{\text {deformation }}$ and $A$ for the present steel were
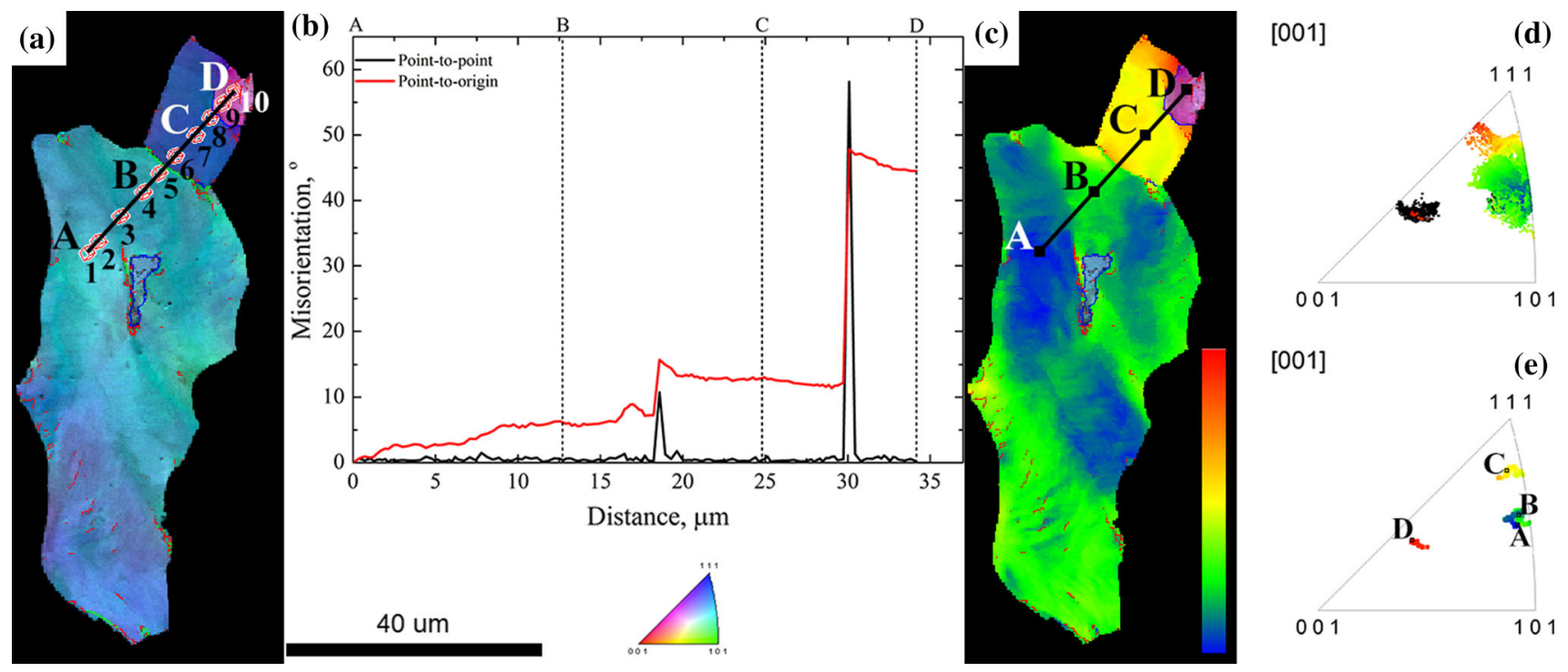

Fig. 6-A close view of grains 1 and 2 from Fig. 2(c). (a) A combined image quality (IQ) and color-coded inverse pole figure (IPF) map with four points (A, B, C, and D) marked in a line from the center to the edge of the grain. The cubes in the map show the local crystal orientation. (b) Misorientation profile, showing the point-to-point and the point-to-origin along the path ABCD. (c) Tolerance angle map. The orientation of point $\mathrm{A}$ is selected as reference and the tolerance value is in the range of $0-25$ deg (shown from blue to red). (d) Inverse pole figure of grains 1 and 2. The black dots correspond to grain 2. (e) Inverse pole figure of the points in the line ABCD. 
calculated, based on the chemical composition, ${ }^{[60]}$ to be $269 \mathrm{~kJ} \mathrm{~mol}^{-1}$ and $2.8 \times 10^{9} \mathrm{~s}^{-1}$. These results further confirm that dynamic recrystallization is a possible mechanism for the formation of the small equiaxed grains (average grain diameter of the grains with size $<15 \mu \mathrm{m}$ is $6.5 \mu \mathrm{m}$ ) at the grain boundaries of elongated grains during deformation with in situ ultrasonic treatment.

\section{SUMMARY}

Tensile deformation with in situ application of ultrasonic vibration was performed on low-carbon DC04 steel samples. The ultrasonic vibration was found to produce a significant and permanent change in the microstructure which was analyzed using optical microscopy, SEM, and EBSD. Sub-grain formation was substantially reduced and the fraction of low-angle grain boundaries decreased by in situ ultrasonic treatment.

The deformation is clearly inhomogeneous, as shown by the mixture of equiaxed grains and very elongated grains giving rise to a bimodal grain size distribution. It was shown through EBSD that significant grain rotation can take place during the process of deformation with in situ ultrasonic treatment. The average grain boundary misorientations increase with the in situ treatment. The formation of the small equiaxed grains at the grain boundaries of elongated grains is attributed to rotational dynamic recrystallization. The lattice in the elongated grain is progressively rotated until high-angle boundaries appear at the equiaxed grain. GROD maps show that the dislocations are primarily concentrated along the grain boundaries for the smaller grains (with average grain diameter $<15 \mu \mathrm{m}$ ), whereas for larger grains (with average grain diameter $>15 \mu \mathrm{m}$ ) they are more homogeneously distributed.

In conclusion, although the exact mechanisms of the development of the bimodal grain size distribution during deformation with in situ ultrasonic treatment are not completely understood, it is becoming obvious that grain boundary rotation plays an important role.

\section{ACKNOWLEDGMENTS}

This research is carried out under Project No. M32.8.09333 in the framework of the Research Program of the Materials innovation institute M2i ( http://www.m2i.nl). The authors thank Allseas Engineering bv for providing the financial support and Applied Ultrasonics Europe for providing the ultrasonic impact treatment tool for the project.

\section{REFERENCES}

1. E.S. Statnikov: International Institute of Welding (IIW); IIW Doc XIII-1667-97, 1997.

2. Y. Kudryavtsev, J. Kleiman, L. Lobanov, V. Knysh, G. Prokopenko: International Institute of Welding (IIW); IIW - Doc XIII-2010-04, 2004.
3. F. Blaha and B. Langenecker: Naturwissenschaften, 1955, vol. 42, p. 556 .

4. B. Langenecker: Proc. Am. Soc. Test Mat., 1962, vol. 62, pp. 602-09.

5. B. Langenecker: IEEE TransSonics Ultrason., 1966, vols. SU-13, pp. 1-8.

6. G.F. Nevill and F.R. Brotzen: Proc. Am. Soc. Test Mat., 1957, vol. 57 , pp. 751-55.

7. G.S. Baker and S.H. Carpenter: Rev. Sci. Instrum., 1965, vol. 36, pp. 29-31

8. R. Pohlman and F. Leehfeldt: Ultrasonics, 1966, vol. 4, pp. 178-85.

9. O.I. Volchok, I.A. Gindin, L.A. Kornienko, I.M. Neklyudov, and A.A. Nikolaenko: Strength Mater., 1982, vol. 14, pp. 565-68.

10. M.D. Tyavlovskii: Met. Sci. Heat Treat., 1981, vol. 23, pp. 412-14.

11. A.E. Eaves, A.W. Smith, W.J. Waterhouse, and D.H. Sansome: Ultrasonics, 1975, vol. 13 (4), pp. 162-70.

12. M. Tanibayashi: Phys. Status Solidi (A) Appl. Res., 1991, vol. 128 (1), pp. 83-94.

13. G.A. Malygin: Phys. Solid State, 2000, vol. 42, p. 72.

14. G.A. Malygin: Phys. Solid State, 2000, vol. 42, p. 492.

15. H.O.K. Kirchner, W.K. Kromp, F.B. Prinz, and P. Trimmel: Mater. Sci. Eng., 1985, vol. 68 (2), pp. 197-206.

16. O. Izumi, K. Oyama, and Y. Suzuki: Trans. Jpn. Inst. Met., 1966, vol. 7 (3), pp. 158-62.

17. Y. Daud, M. Lucas, and Z. Huang: J. Mater. Process. Technol., 2007, vol. 186 (1-3), pp. 179-90.

18. O. Izumi, K. Oyama, and Y. Suzuki: Trans. Jpn. Inst. Met., 1966, vol. 7 (3), pp. 162-67.

19. T. Endo, K. Suzuki, and M. Ishikawa: Trans. Jpn. Inst. Met., 1979, vol. 20 (12), pp. 706-12.

20. Z. Huang, M. Lucas, and M.J. Adams: Ultrasonics, 2002, vol. 40 (1-8), pp. 43-48.

21. Y. Daud, M. Lucas, and Z. Huang: Ultrasonics, 2006, vol. 44 (SUPPL), pp. e511-15.

22. R.K. Dutta, R.H. Petrov, R. Delhez, M.J.M. Hermans, I.M. Richardson, and A.J. Böttger: Acta Mater., 2013, vol. 61 (5), pp. $1592-602$.

23. ASTM E8/E8M - 09: Annual Book of ASTM Standards 2009, 2009.

24. ASM Handbook: Metallography and Microstructures, vol. 9. ASM International, 2004.

25. S. Zaefferer: Ultramicroscopy, 2007, vol. 107 (2-3), pp. 254-66.

26. F.J. Humphreys: J. Mater. Sci., 2001, vol. 36 (16), pp. 3833-54.

27. M. Jedrychowski, J. Tarasiuk, B. Bacroix, and S. Wronski: J. Appl. Crystallogr., 2013, vol. 46 (2), pp. 483-92.

28. M. Kamaya, A.J. Wilkinson, and J.M. Titchmarsh: Acta Mater., 2006, vol. 54 (2), pp. 539-48.

29. M. Kamaya: Mater. Charact., 2012, vol. 66, pp. 56-67.

30. B. Derby: Acta Metall. et Mater., 1991, vol. 39 (5), pp. 955-62.

31. M.A. Meyers, Y.B. Xu, Q. Xue, M.T. Pérez-Prado, and T. McNelley: Acta Mater., 2003, vol. 51 (5), pp. 1307-25.

32. Y. Zou, W. Qin, E. Irissou, J.G. Legoux, S. Yue, and J.A. Szpunar: Scripta Mater., 2009, vol. 61 (9), pp. 899-902.

33. J.C. Tan and M.J. Tan: Mater. Sci. Eng. A, 2003, vol. 339 (1-2), pp. 124-32.

34. Y. Xu, H.J. Yang, and M.A. Meyers: Scripta Mater., 2008, vol. 58 (8), pp. 691-94.

35. Q. Li, Y.B. Xu, Z.H. Lai, L.T. Shen, and Y.L. Bai: Mater. Sci. Eng. A, 2000, vol. 276 (1-2), pp. 250-56.

36. M.A. Meyers and H.R. Pak: Acta Metall., 1986, vol. 34 (12), pp. 2493-99.

37. M.A. Meyers, G. Subhash, B.K. Kad, and L. Prasad: Mech. Mater., 1994, vol. 17 (2-3), pp. 175-93.

38. U. Andrade, M.A. Meyers, K.S. Vecchio, and A.H. Chokshi: Acta Metall. Et Mater., 1994, vol. 42 (9), pp. 3183-95.

39. V.F. Nesterenko, M.A. Meyers, J.C. LaSalvia, M.P. Bondar, Y.J. Chen, and Y.L. Lukyanov: Mater. Sci. Eng. A, 1997, vol. 229 (12), pp. 23-41.

40. D.A. Hughes, R.A. Lebensohn, H.R. Wenk, and A. Kumar: Proc. R. Soc. Lond. A, 2000, vol. 456, pp. 921-53.

41. D. Kuhlmann-Wilsdorf and N. Hansen: Scripta Metall. et Mater., 1991, vol. 25 (7), pp. 1557-62.

42. B. Bay, N. Hansen, D.A. Hughes, and D. Kuhlmann-Wilsdorf: Acta Metall. et Mater., 1992, vol. 40 (2), pp. 205-19.

43. Q. Liu and N. Hansen: Scripta Metall. et Mater., 1995, vol. 32 (8), pp. 1289-95. 
44. D.A. Hughes, D.C. Chrzan, Q. Liu, and N. Hansen: Phys. Rev. Lett., 1998, vol. 81 (21), pp. 4664-67.

45. M.T. Pérez-Prado, G. González-Doncel, O.A. Ruano, and T.R. McNelley: Acta Mater., 2001, vol. 49 (12), pp. 2259-68.

46. H.S. Kim, D.H. Joo, M.H. Kim, S.K. Hwang, S.I. Kwun, and S.W. Chae: Mater. Sci. Technol., 2003, vol. 19 (3), pp. 403-405.

47. F.J. Humphreys and M. Hatherly: Recrystallization and Related Annealing Phenomena, Pergamon Press, Oxford, 1995.

48. P.B. Prangnell, J.S. Hayes, J.R. Bowen, P.J. Apps, and P.S. Bate: Acta Mater., 2004, vol. 52 (11), pp. 3193-3206.

49. Y. Liu, S. Suslov, Q. Han, L. Hua, and C. Xu: Metall. Mater. Trans. A, 2013, vol. 44A, pp. 3232-44.

50. R.B. Lindsay: Mechanical Radiation, McGraw-Hill, New York, 1960.

51. K.H. Westmacott and B. Langenecker: Phys. Rev. Lett., 1965, vol. 14 (7), pp. 221-22.

52. R. Dawson and D.G. Moffat: J. Eng. Mater. Technol. Trans. ASME, 1980, vol. 102 (1), pp. 169-76.
53. D. Rao, D. Wang, L. Chen, and C. Ni: Int. J. Fatigue, 2007, vol. 29 (1), pp. 192-96.

54. S. Kwofie: Mater. Sci. Eng. A, 2009, vol. 516 (1-2), pp. 154-61.

55. J.S. Wang, C.C. Hsieh, C.M. Lin, C.W. Kuo, and W. Wu: Metall. Mater. Trans. A, 2013, vol. 44A, pp. 806-18.

56. A. Mutrux, B. Berisha, and P. Hora: J. Mater. Process. Technol., 2011, vol. 211 (8), pp. 1448-56.

57. H.F. Chai and C. Laird: Mater. Sci. Eng., 1987, vol. 93 (C), pp. $159-74$.

58. Y. Liu, S. Suslov, Q. Han, C. Xu, and L. Hua: Mater. Lett., 2012 , vol. 67 (1), pp. 52-55.

59. B. Derby: Scripta Metall. et Mater., 1992, vol. 27 (11), pp. 1581-85.

60. S.F. Medina and C.A. Hernandez: Acta Mater., 1996, vol. 44 (1), pp. $137-48$.

61. C.A. Hernandez, S.F. Medina, and J. Ruiz: Acta Mater., 1996, vol. 44 (1), pp. 155-63.

62. F. Montheillet, O. Lurdos, and G. Damamme: Acta Mater., 2009, vol. 57 (5), pp. 1602-12. 